\title{
An imperfect vision of indivisibility in the Sustainable Development Goals
}

\author{
Philip J.K. McGowan ${ }^{1}$, Gavin B. Stewart*1, Graham Long ${ }^{2+}$, Matthew J. Grainger ${ }^{1+}$. \\ ${ }^{1}$ School of Natural and Environmental Sciences, Newcastle University, NE1 7RU, United Kingdom. \\ ${ }^{2}$ School of Geography, Politics and Sociology, Newcastle University, NE1 7RU, United Kingdom. \\ +Joint last Authors \\ *corresponding author Gavin.stewart@newcastle.ac.uk
}

\section{Main text}

The Sustainable Development Goals (SDGs) are presented as highly connected: an 'interrelated' and 'indivisible' agenda with need of policy coherence for implementation. We analyse the relationships among SDGs using formal systems analysis and find that the connections between Goals are uneven, with a failure to integrate gender equality, and peace and governance concerns. This incoherence may undermine policy initiatives aimed to develop approaches to implement the SDGs.

The SDGs were adopted by United Nations member states in September $2015^{1}$ in the 2030 Agenda for Sustainable Development. They describe a "plan of action for people, planet and prosperity" to "stimulate action over the next 15 years in areas of critical importance for humanity and the planet". The SDGs are presented as "integrated and indivisible", whilst acknowledging differing priorities and capacities between countries, where responsibility for delivery lies ${ }^{1}$.

The indivisible nature of the SDGs is widely advanced as axiomatic ${ }^{1,2,3}$ and underpins assessment of "policy coherence", providing a basis for consideration of where incoherence would be most costly. A growing body of literature aims to track these interlinkages ${ }^{2,4}$ and a community of practice is mobilised around policy coherence ${ }^{2,5}$. This is a central constituent of the "science-policy" interface, with a distinctive role for science to guide policy. As ICSU's 2017 report contends: "All SDGs interact with one another - by design they are an integrated set of global priorities and objectives that are fundamentally interdependent" ${ }^{\prime 2}$. Integration was emphasised in the presentation of the 2030 Agenda in response to a perceived need to "flag more clearly... the integrated nature of the new goals and targets", and to encourage a move away from "siloed" implementation ${ }^{7}$. However, not all analyses of the SDGs find the same level of interdependence. LeBlanc ${ }^{8}$, for example, analyses overlaps in wording and finds that the interconnectedness is uneven. Our study carries out a formal systems analysis aiming to provide a deeper understanding of the relationships between Goals. Unlike LeBlanc's work which, he acknowledges, is limited to the wording of the targets, we use The International Council for Science's account of the relations between the targets of different Goals,

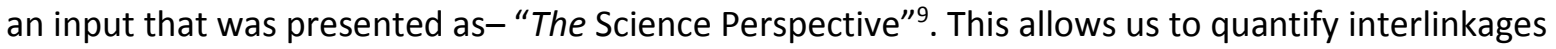
between Goals. Our analysis shows that the interlinkages between Goals are reflected in partial linkages at target level. Furthermore, where we expect there to be strong, necessary connections reflected in the SDGs, these are absent from the way that expert opinion characterises interlinkages.

The SDG network is highly connected (connectivity 0.8 , reciprocity 0.79 ) but there is variation amongst the Goals in terms of different measures of centrality (degree, strength, closeness, and betweenness; Table 1). 
Quality Education was ranked in the top three Goals for three of the four metrics: Reducing Hunger and Affordable and Clean Energy for two, and Clean Water and Sanitation, Industry, Innovation and Infrastructure and Life on Land in one (Figs $1 \& 2$ ). No Poverty was listed in the top three for two metrics (betweenness and closeness) but the bottom three for strength (Figs $1 \& 2$ ). This reflects the fact that Poverty links to most of the other Goals but only through a few targets (mean \pm standard deviation: $1.55 \pm 0.69$ ) when compared with the other Goals $(4.10 \pm 2.90)$. Good Health and Wellbeing was ranked top for one metric (strength) and in the bottom three for two others (betweenness and closeness). Health has a high number of links to each Goal (9.27 \pm 2.71 ); there are many Health targets that are directly related to other Goals but relatively few targets coming from other Goals to Health, hence the low betweenness and closeness scores (Figs 1 \& 2). Strikingly, Sustainable Cities and Communities was ranked in the bottom three for all four metrics and was lowest for three of them (Figs 1 \& 2). Other Goals that were low ranked were Responsible Production and Consumption, Peace, Justice and Strong Institutions Gender Equality, Reduced Inequalities, and Life Below Water (Figs 1 \& 2). Climate Action and Decent Work and Economic Growth were mid-ranking in all metrics (Figs $1 \& 2$ ).

The significance of this unevenness, and its causes, merits further investigation. In the case of peace and gender equality, the lack of connection is striking and puzzling. The rhetoric around the SDGs claims that gender equality and peace are both central to, and necessary for, sustainable development. The preamble to the 2030 Agenda $^{1}$, claims that both are crucial. There may be reasons why gender equality and peace are emphasised as integral. Notably, in the case of peace, there had been a debate earlier in the process over whether peace and governance were within the proper remit of this agreement at all ${ }^{7}$. The centrality of both are supported, both by empirical investigation (e.g. ${ }^{10,11,12}$ ) and also logical and conceptual necessity. It is difficult to conceive of a satisfactory account of sustainable development that does not value the wellbeing of women as much as men, or a definition of development that does not value not just "freedom from want" but also "freedom from fear" as constituent parts. Why, then, are these strong constitutive relationships not reflected in the systems analysis? Three avenues warrant further investigation:

First, analyses of Goals, targets (and indicators) are exposed to ambiguity generated by weakly defined terms. It may be that the mismatch is a feature of the language employed, and a future strand of SDG research would usefully address questions of definition.

Second, the problem may be the content rather than the expression of the SDGs themselves. The content of Goals and targets was politically determined, and may imperfectly express the fundamental interconnectedness of the sustainable development agenda. Addressing this would require that the Goals and targets - or, over time, a body of knowledge around them - reflect better the state of knowledge on interconnections, specifically where they are strong or weak, and the associated uncertainties.

Third, because our method uses the ICSU expert analysis as its starting point, it reflects the way that these experts have drawn (or not drawn) the links. The suggestion - certainly worth investigation is that this analysis is somehow partial or skewed. Using evidence from meta-analysis or other forms of research synthesis to characterise these links might yield important insights in any or all of these areas.

The high degree of inter-connectedness of the SDGs suggests that a targeted approach to prioritisation will have direct and indirect costs, albeit of unknown magnitude - but also that there are areas where such incoherence might be minimal ${ }^{13}$. The robustness of the agenda - the breadth and depth of interconnection - implies that it survives, as a network, even when only partially implemented. Clearly, too, the interrelation is not equally apportioned. Conventional presentations of sustainable development insist on equally important 'pillars'; prominent visualisations of 
sustainable development -the doughnut mode ${ }^{14}$ especially - represent the different facets of planetary boundaries and social foundations as spatially equal suggesting equal status. How might the unequal interconnections affect such portrayals? This is a question for further research.

Our analysis does not identify optimal policy "entry point(s)" into the SDG nexus. The SDGs are nationally differentiated, and delivered at country level where national contexts influence policy choice and prioritisation - reflecting, political judgements on the comparative urgency of different areas and available capacity, which change the weight accorded each of the Goals and whether interconnections present in theory can be realised in practice. The alternative geometries of evidence-based country level inter-relationships will undoubtedly pose new questions regarding coherence.

All of this indicates a highly complex process for nationally differentiated-yet-universal implementation of the SDGs. It suggests that there is considerable need for both evidence-based approaches and more abstract reflection on how sustainable development is being portrayed and understood.

\section{Methods}

We undertook a formal systems analysis that quantifies the relationships between SDGs. Details are reported in Supplementary Information S1.

Data availability

The data and code that support the findings of this study are available in Supplementary Information S1.

\begin{tabular}{|l|l|l|}
\hline \multicolumn{1}{|c|}{ Metric } & \multicolumn{1}{|c|}{ What it measures about the SDGs } & \multicolumn{1}{c|}{$\begin{array}{c}\text { How it is calculated (see the S1 for } \\
\text { more details) }\end{array}$} \\
\hline Network level metrics & $\begin{array}{l}\text { Highly connected networks mean that } \\
\text { each SDG is to some extent reliant on } \\
\text { the other SDGs and, therefore, there } \\
\text { are no independent groupings of SDGs }\end{array}$ & $\begin{array}{l}\text { L/(N*(N-1)) where L=Links and } \\
\text { N=Nodes. This yields a score between } \\
\text { Oand 1 where a totally unconnected } \\
\text { network scores 0 and a fully connected } \\
\text { network 1. }\end{array}$ \\
\hline Reciprocity & $\begin{array}{l}\text { High scores mean that there are } \\
\text { reciprocal targets between Goals }\end{array}$ & $\begin{array}{l}\text { The probability (between 0 and 1) that } \\
\text { the opposite counterpart of a directed } \\
\text { link is also included in the graph. }\end{array}$ \\
\hline Node (=Goal) level metrics & $\begin{array}{l}\text { This measures the number of links } \\
\text { going in to or out of the node - in this } \\
\text { context, the number of targets of one } \\
\text { Goal that link to other Goals. There are } \\
\text { two component measures: those } \\
\text { targets coming from a Goal (i.e. are } \\
\text { influenced by the Goal) and those } \\
\text { targets going to a Goal (i.e. which } \\
\text { influence the Goal) }\end{array}$ & $\begin{array}{l}\text { Degree assigns importance scores } \\
\text { based on the number of links going in } \\
\text { to and out of nodes (measured as "in" } \\
\text { degree, "out" degree and "total" } \\
\text { degree. A node with a greater number } \\
\text { of links is considered to be more } \\
\text { central (and thus more important) in } \\
\text { the network. }\end{array}$ \\
& $\begin{array}{l}\text { This measures the total number of } \\
\text { links from a node and combines this } \\
\text { with the score from the nearest }\end{array}$ & $\begin{array}{l}\text { An extension of node degree that } \\
\text { measures the total weight of a node's } \\
\text { connected links combined with that of }\end{array}$ \\
\hline
\end{tabular}




\begin{tabular}{|l|l|l|}
\hline & $\begin{array}{l}\text { neighbours. High strength, therefore, } \\
\text { means that a node is more connected } \\
\text { to nodes close to it than to other } \\
\text { nodes. This reveals whether there are } \\
\text { some groups of Goals that are more } \\
\text { closely connected (through targets) } \\
\text { than others }\end{array}$ & $\begin{array}{l}\text { its nearest neighbours. If links vary in } \\
\text { weight then this will differ in value to } \\
\text { that of degree. }\end{array}$ \\
\hline Closeness & $\begin{array}{l}\text { This indicates how central a Goal is in } \\
\text { the network: a highly connected Goal } \\
\text { is more central. }\end{array}$ & $\begin{array}{l}\text { This calculates the distance from a } \\
\text { node to all other nodes in the network. } \\
\text { A shorter distance indicates greater } \\
\text { centrality }\end{array}$ \\
\hline Betweenness & $\begin{array}{l}\text { This shows how nodes are situated in } \\
\text { the graph and so measures the flow of } \\
\text { information through the network. An } \\
\text { SDG with high betweenness will be an } \\
\text { important SDG to address because it } \\
\text { will have many shared target links to } \\
\text { and from other Goals }\end{array}$ & $\begin{array}{l}\text { The number of shortest path from all } \\
\text { nodes to all others that pass through } \\
\text { the focal node. As igraph interprets } \\
\text { link weights as path costs rather than } \\
\text { path strengths we calculated this with } \\
\text { all links equally weighted. }\end{array}$ \\
\hline
\end{tabular}

Table 1. Graph characteristics and implications for SDGs.

Gavin Stewart is the author to whom correspondence and requests for materials should be addressed.

\section{Competing interests}

The authors do not have any competing interests

\section{Acknowledgements}

The work was unfunded. GS would like to acknowledge the support of Emma and Rosie as well as the Modelling Evidence \& Policy Research Group through challenging personal circumstances whilst this research was underway.

\section{Author contributions}

The idea was conceived by GS and PM; GL led on the political dimensions of the work and MG led and undertook analyses. All authors contributed equally in production of the manuscript and the work was collaborative requiring unique inputs from all authors.

\section{References}

1. United Nations http://www.un.org/ga/search/view doc.asp?symbol=A/RES/70/1\&Lang=E (2015)

2. D.J. Griggs, M. Nilsson, A. Stevance, D. McCollum. https://www.icsu.org/publications/aguide-to-sdg-interactions-from-science-to-implementation. (2017)

3. Biermann, F. and Kanie N.eds. ISBN 9780262533195. MIT Press. (2017)

4. Nunes AR, Lee K, O'Riordan T. BMJ Glob Health. ; 1(3): e000068. (2016)

5. OECD Publishing, Paris, http://dx.doi.org/10.1787/9789264301061-en. OECD (2018)

6. UN-DESA http://workspace.unpan.org/sites/Internet/Documents/UNPAN94443.pdf (2015)

7. Dodds F., Donoghue D., and Roesch J L. ISBN 9781315527086. Routledge (2017)

8. LeBlanc, D. (2015) Sustainable Development 23: 176-187. 
9. ICSU. https://www.icsu.org/publications/review-of-targets-for-the-sustainabledevelopment-goals-the-science-perspective-2015. (2015)

10. IMF Working Paper WP/16/111. https://www.imf.org/external/pubs/ft/wp/2016/wp16111.pdf. (2016)

11. Collier, P. ISBN 9780195374636. Oxford University Press. (2008)

12. Fukuda-Parr, S. Research Paper 32, UNU-WIDER. (2007)

13. Nilsson, M, Griggs, D and Visbeck, M. Nature 534, 320-322. (2016)

14. Raworth, K. https://www.oxfam.org/sites/www.oxfam.org/files/dp-a-safe-and-just-spacefor-humanity-130212-en.pdf (2012)

\section{Figure legends}

Figure One: Variation in the network characteristics of the Sustainable Development Goals. Goals are scaled in relation to scores for Degree, Strength, Closeness and Betweenness centrality metrics (see Supplementary Methods 1 ). The number of each Goal is adjacent to the nodes and numbering is as follows: No Poverty (Goal 1); Reducing Hunger (Goal 2); Good Health and Well-being (Goal 3); Quality Education (Goal 4); Gender Equality (Goal 5); Clean Water and Sanitation (Goal 6); Affordable and Clean Energy (Goal 7); Decent Work and Economic Growth (Goal 8); Industry, Innovation and Infrastructure (Goal 9); Reduced Inequalities (Goal 10); Sustainable Cities and Communities (Goal 11) ; Responsible Production and Consumption (Goal 12); Climate Action (Goal 13); Life Below Water (Goal 14); Life on Land (Goal 15);Peace, Justice and Strong Institutions (Goal 16). Goal 17 (Partnerships for the Goals) was not included in the analysis.

Figure Two: Ranking of the Interconnectedness of Sustainable Development Goals using network metrics. Goals were ranked on the scores of Degree, Strength, Closeness and Betweenness centrality metrics (see Supplementary Methods 1) with the highest scores ranked 1 and the lowest ranked 16. 

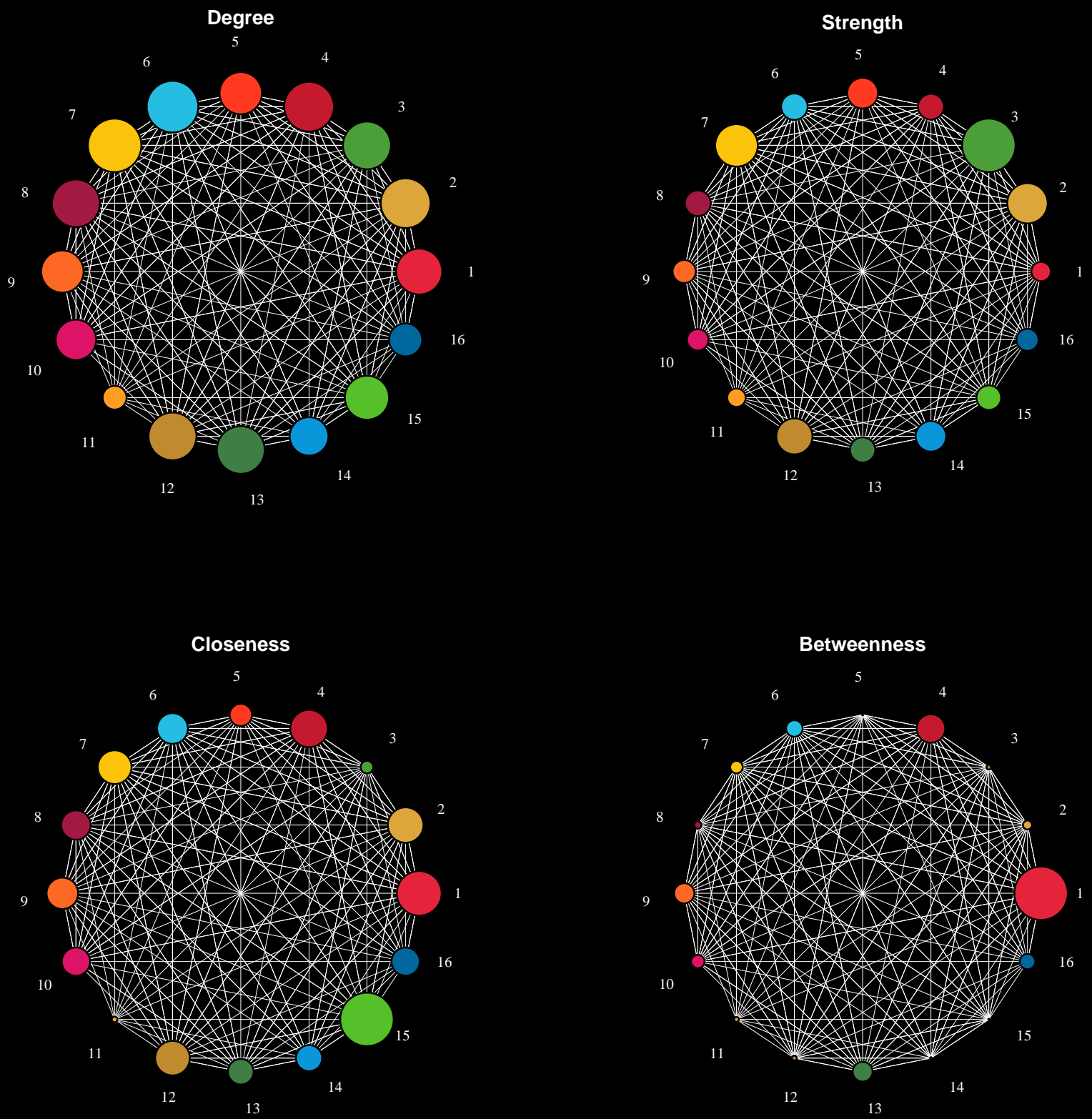


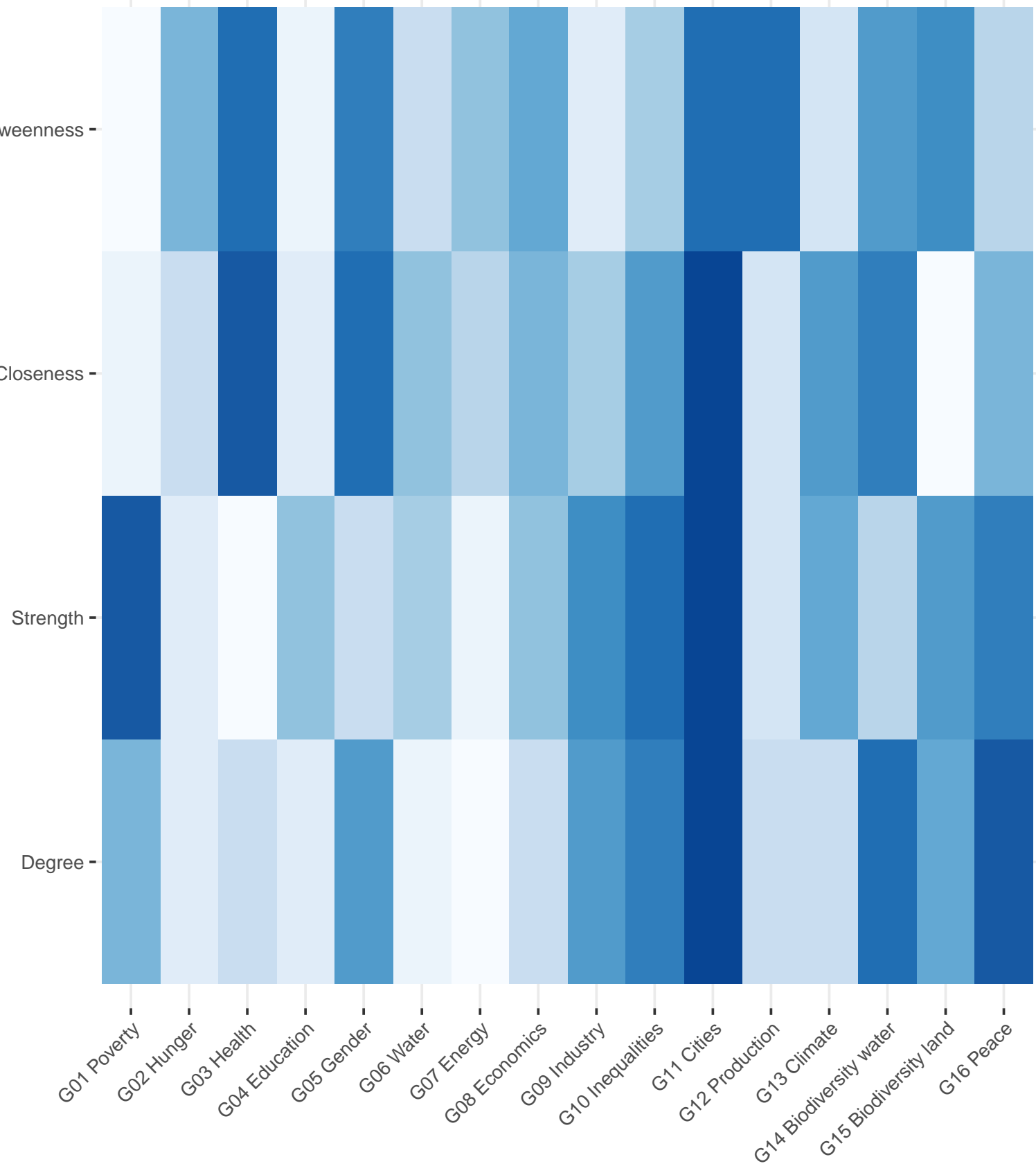

Rank 